\title{
PERITONITIS Y PELVIPERITONITIS
}

\author{
Manejo y tratamiento en el Servicio de Sépticas del Instituto \\ Materno Infantil "Concepción Villaveces de Acosta" de Bogetá
}

\author{
Dr. Armando Lozano Carrillo*
}

\begin{abstract}
EL PRESENTE TRABAJO SE REFIERE A UN GRUPO DE 29 PACIENTES CON DIAGNOSTICO DE PELVIPERITONITIS O PERITONITIS GENERALIZADA, SOBRE UN TOTAL DE 200 PACIENTES ATENDIDAS EN EL SERVICIO DE SEPTICAS DEL INSTITUTO MATERNO INFANTIL, DIRIGIDO POR LOS DOCTORES LUIS SANTAMARIA Y GUILLERMO CASTRO.
\end{abstract}

\section{MATERIAL Y METODOS}

Como se anotó anteriormente el material se obtuvo del Servicio de Sépticas del I. M. I., sobre 200 pacientes atendidas en el período comprendido entre el 1 . de Marzo al 31 de Agosto de 1965; de las cuales 20 con diagnóstico de Peritonitis para un $10 \%$ y 9 con diagnóstico de Pelviperitonitis para un $4.5 \%$.

Para el diagnóstico y tratamiento de estas pacientes se tuvo en cuenta principalmente la sintomatología de ingreso dando especial importancia al dolor abdominal, fiebre, aspecto $y$ frecuencia del vómito, diarrea y antecedentes de maniobras abortivas, tratando de establecer los métodos usados, condiciones de asepsia y antisepsia, la ocupación de la persona que las ejecuta y el tiempo transcurrido entre la realización de las maniobras y el día de consulta de la paciente. Se valoró también el estado

* Residente II de Obstetricia y Ginecología de la Universidad Nacional de Colombia. de hidratación, la coloración de la piel y mucosas, los signos de distensión abdominal y defensa muscular, el dolor que provoca la palpación, la disminución o ausencia de ruidos intestinales, el examen ginecológico, los exámenes de laboratorio especialmente el cuadro hemático y la $\mathrm{V}$. S. G., el estudio radiológico de abdomen simple tanto en posición horizontal como vertical, los cultivos de material obtenido por frotis de restos ovulares, frotis de secreción endocervical, colpocentesis, colpotomía - laparotomía y por último el diagnóstico de Anatomía Patológica.

De las 29 pacientes tuve la oportunidad de tratar médica y quirúrgicamente a 12 y de ayudar en la cirugía de 7 más.

Como se aprecia en el Cuadro № 1, el promedio de edad es de 26.8 variando entre los 18 y 38 años, el promedio de gestación en semanas 6.37 correspondiendo la mayoría a embarazos de 6 a 9 semanas. 
CUADRO N: 1

PROMEDIO DE EDAD, GESTACION Y PERMANENCIA HOSPITALARIA

\begin{tabular}{|c|c|c|c|}
\hline & Promedio & & Variación \\
\hline Edad & 26.8 & 18 & a 38 años \\
\hline Gestación & 6.37 & 4 & a 17 semanas \\
\hline Permanencia & & & \\
\hline hospitalaria & 24.4 & 4 & a 67 días \\
\hline
\end{tabular}

El promedio de permanencia hospitalaria es de 24.4 variando entre 4 y 67 días, el cual es un poco alto debido a que entre las complicaciones más frecuentes figura la infección de la herida quirúrgica la cual tiene que cicatrizar por segunda intención.

En relación con la paridad y antecedentes de maniobras abortivas correspondió en esta oportunidad el $75.17 \%$ para las multigestantes, el $17.24 \%$ para primigestantes y el $6.89 \%$ para las multigestantes.

\section{CUADRO NN 2}

PARIDAD Y ANTECEDENTES DE MANIOBRAS ABORTIVAS

\begin{tabular}{lcc}
\hline & Casos & Porcentaje \\
\hline Nuligestantes & 2 & $6.89 \%$ \\
Primigestantes & 5 & $17.24 \%$ \\
Multigestantes & 22 & $75.17 \%$ \\
Confesaron maniobras abort. & 20 & $68.9 \%$ \\
Negaron maniobras abortivas & 9 & $31.14 \%$ \\
\hline
\end{tabular}

Confesaron maniobras abortivas el $68.9 \%$ de las pacientes. Dichas maniobras fueron practicadas por comadronas, con sonda de caucho y la mayoría sin espéculo ni guantes.

De los dos casos de multigestantes, una confesó maniobras abortivas y la otra ingresó con diagnóstico de Pelviperitonitis y Miomatosis Uterina desarrollando posteriormente Peritonitis generalizada.

Los síntomas más frecuentes son: calofrío, dolor abdominal, hemorragia genital, fiebre, vómito, diarrea y náuseas.
CUADRO NN 3

SINTOMATOLOGIA

\begin{tabular}{lcc}
\hline Síntomas & Casos & Porcentaje \\
\hline Calofrío & 29 & $100.00 \%$ \\
Dolor abdominal & 24 & $82.75 \%$ \\
Hemorragia genital & 22 & $75.17 \%$ \\
Fiebre & 19 & $65.51 \%$ \\
Vómito & 9 & $31.03 \%$ \\
Diarrea & 4 & $13.79 \%$ \\
Náuseas & 4 & $13.79 \%$ \\
\hline
\end{tabular}

En el Servicio de Sépticos del I. M. I., se clasifican las pacientes en cuatro estados de acuerdo al cuadro clínico y sejún la gravedad y extensión del proceso séptico así: (1) Estado I cuando el proceso infeccioso está localizado al endometrio. Estado II cuando compromsto los anzxos. Estado III cuando el proceso ha invadido el peritoneo pélvico 0 abdominal. Estado IV cuando hay manifestaciones de septicemia, shock bacteriémico, o insuficiencia renal aguda. De acuerdo con la anterior clasificación de las 29 pacientes de este trabajo el $72.41 \%$ ingresaron con diagnóstico de sepsis estado III, el $24.13 \%$ estado 11 y el $3.44 \%$ estado 1 , es decir que 8 pacientes no presentaban un cuadro peritoneal franco a su ingreso.

CUADRO № 4 DIAGNOSTICO DE INGRESO

\begin{tabular}{lcc}
\hline Estado & Casos & Porcentaje \\
\hline Estado III & 21 & $72.41 \%$ \\
Estado II & 7 & $24.13 \%$ \\
Estado I & 1 & $3.44 \%$ \\
\hline
\end{tabular}

CUADRO N: 5

CUADRO HEMATICO V. S. G. Y PROTEINEMIA

\begin{tabular}{lrrl}
\hline & Promedio & \multicolumn{1}{c}{ Variación } \\
\hline Hematocrito & 26.93 & 21 a 38 \\
Hemoglobina & 9.56 & 6.4 a 13.7 \\
Leucocitos & 12.350 & 7.800 a 30.000 \\
Neutrófilos & 75.27 & 50 a $94 \%$ \\
V. S. G. & 47.24 & 6 a 72 \\
Proteinemia & 4.17 & 2.54 a 8.02 \\
\hline
\end{tabular}


Todas estas pacientes presentaron anemia, leucocitosis y neutrofilia.

Los cultivos mostraron infección por E. Coli, Estafilococo albus no hemolítico, Subtilis y Diplococo, siendo la asociación más frecuente E. Coli y Estafilococo Albus no Hemolítico. Se practicaron 11 hemocultivos los cuales fueron negativos.

\section{CUADRO N: 6}

\begin{tabular}{lcr}
\multicolumn{3}{c}{ CULTIVos } \\
\hline & Casos & Porcentajes \\
\hline E. Coli & 17 & $58.62 \%$ \\
Estafilococo Albus & 17 & $58.62 \%$ \\
no Hemolítico & 2 & $6.89 \%$ \\
Subtilis & 1 & $3.44 \%$ \\
Diplococo & 4 & $13.79 \%$ \\
Cultivos negativos & 11 de 11 & $100.00 \%$ \\
Hemocultivos negativos &
\end{tabular}

El estudio radiológico de abdomen simple fue positivo para peritonitis ○ reacción peritoneal en el $27.58 \%$ en tanto que resultó negativo en el $44.82 \%$. Los radiólogos explican este alto porcentaje de informes negativos debido a que no existe un cuadro radiológico característico de Peritonitis.

\section{CUADRO № 7}

\section{ESTUDIO RADIOLOGICO}

\begin{tabular}{lcc}
\hline Rx & Casos & Porcentaje \\
\hline Positivos & 9 & $27.58 \%$ \\
Negativos & 13 & $44.82 \%$ \\
No se hizo & 8 & $27.58 \%$ \\
\hline
\end{tabular}

Manejo. A pesar de que en la mayoría de los antibiogramas se informó resistencia, poca sensibilidad o no se hizo referencia a la Penicilina, se observó que esta suministrada a dosis masivas de 30 a 60 millones al día por vía intravenosa y asociada a Cloranfenicol en dosis de 3 a 4 grs., al día también por vía intrave- nosa fué suficiente en la mayoría de los casos para controlar el proceso infeccioso.

\section{CUADRO NN 8}

\section{Anžibióticos}

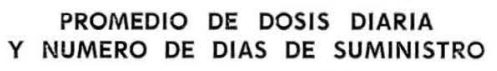

PROMEDIO DE DOSIS DIARIA $Y$ NUMERO DE DIAS DE SUMINISTRO

\begin{tabular}{lcccc}
\hline Antibiótico & Dosis diaria & $N^{0}$ de días \\
\hline Novobiocina & 1 gr. & 6 & \\
Cloranfenicol & 1 a 4 grs. & 8 a 10 \\
Polimicina & 4 & millones & 8 a 10 \\
Penicilina cristalina & 27 & millones & 5 a 12 \\
Penicilina procaínica & 14.37 millones & 1 a 14 \\
Oxitetraciclina & 1 a 4 grs. & 2 a 9 \\
\hline
\end{tabular}

A todas las pacientes a quienes se les practicó laparotomía se les dejó 500 mgrs. de Rifamicina en la cavidad abdominal.

Al $86.20 \%$ de estas pacientes se les practicó raspado uterino antes 0 en un solo acto quirúrgico con la colpotomía o la laparotomía. Laparotomía al $72.41 \%$, colpotomía al $37.93 \%$, salpingectomía al $10.34 \%$ por proceso anexial severo, histerectomía en dos casos por presentar miomatosis uterina concomitante con el proceso peritoneal, ooforectomía en un caso por presentar Quiste Dermoide en ovario derecho. A esta paciente se le había practicado raspado uterino por aborto incompleto 8 días antes de su ingreso al Servicio.

\section{CUADRO NN 9}

(1)

\section{INTERVENCIONES QUIRURGICAS}

\begin{tabular}{lcc}
\hline Intervención & Casos & Porcentaje \\
\hline Raspado uterino & 25 & $86.20 \%$ \\
Laparotomía & 21 & $72.41 \%$ \\
Colpotomía & 11 & $37.93 \%$ \\
Salpingectomía & 3 & $10.34 \%$ \\
Histerectomía & 2 & $6.89 \%$ \\
Ooforectomía por Q. Dermoide & 1 & $3.44 \%$ \\
\hline
\end{tabular}


CUADRO N: 10

(2)

INTERVENCIONES QUIRURGICAS

\begin{tabular}{lrc}
\hline Intervención & Casos & Porcentaje \\
\hline Laparotomía y raspado uterino & 12 & $41.37 \%$ \\
Laparot. Rasp. y colpotomía & 6 & $20.69 \%$ \\
Raspado uterino & 5 & $17.24 \%$ \\
Raspado y colpotomía & 3 & $10.34 \%$ \\
Laparotomía & 2 & $6.89 \%$ \\
Laparotomía y colpotomía & 1 & $3.44 \%$ \\
\hline
\end{tabular}

El control de electrolitos en el post-operatorio no mostró variaciones significativas, solamente el Potasio mostró tendencia a permanecer por encima de $5 \mathrm{mEq}$.

\section{CUADRO N: 11}

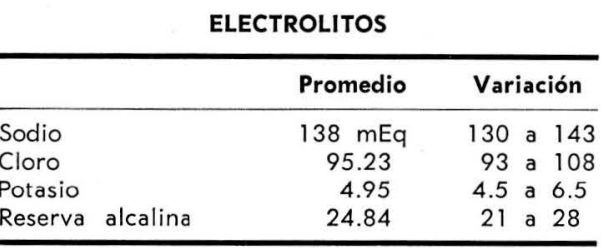

Los diagnósticos de Anatomía Patológica fueron: Restos ovulares, Peritonitis, Salpingitis aguda y crónica, Endometritis, Endometrio proliferativo, Decidua necrótica, Miomatosis uterina, Endometrio secretor, Quiste dermoide y Kimmestiel Wilson.

CUADRO N: 12

DIAGNOSTICOS ANATOMOPATOLOGICOS

\begin{tabular}{lcc}
\hline Diagnóstico & Casos & Porcentaje \\
\hline Restos ovulares & 14 & $48.26 \%$ \\
Peritonitis & 13 & $44.82 \%$ \\
Salpingitis aguda y crónica & 5 & $17.24 \%$ \\
Endometrio Proliferativo & 5 & $17.24 \%$ \\
Endometritis & 2 & $6.89 \%$ \\
Decidua necrótica & 2 & $6.89 \%$ \\
Miomatosis uterina & 2 & $6.89 \%$ \\
Endometrio Secretor & 1 & $3.44 \%$ \\
Quiste Dermoide & 1 & $3.44 \%$ \\
Kimmestiel Wilson & 1 & $3.44 \%$ \\
\hline
\end{tabular}

Para el manejo de estas pacientes se dió gran importancia al control estricto de líquidos, succión gástrica continua, cateterismo de la vena safena interna preferencialmente, teniendo cuidado de lavar el catéter de polietileno cada tercer día con una solución heparinizada, transfusión sanguínea de acuerdo con el grado de anemia, dieta hiperproteica y administración de Anabólicos por vía oral o parenteral.

Complicaciones. Las complicaciones más frecuentes fueron: infección de la herida quirúrgica, absceso subfrénico, neumonía, fístula intestinal, absceso de cúpula, pielonefritis, insuficiencia cardíaca, edema pulmonar, coma ácidocetócico y absceso glúteo. Hubo un caso de hipertensión arterial $(14 \times 11)$ después de un tratamiento prolongado con Polimicina, se suspendió el antibiótico y la tensión se normalizó tres días después.

CUADRO № 13

\section{COMPLICACIONES POST-OPERATORIAS}

\begin{tabular}{lcc}
\hline Complicaciones & Casos & Porcentaje \\
\hline Infección de la herida & 10 & $34.48 \%$ \\
Neumonía & 3 & $10.34 \%$ \\
Absceso subfrénico & 3 & $10.34 \%$ \\
Fístula intestinal & 2 & $6.89 \%$ \\
Absceso de cúpula & 1 & $3.44 \%$ \\
Absceso glúteo & 1 & $3.44 \%$ \\
Coma ácido cetócico & 1 & $3.44 \%$ \\
Edema pulmonar & 1 & $3.44 \%$ \\
Hipertensión arterial & 1 & $3.44 \%$ \\
Insuficiencia cardíaca & 1 & $3.44 \%$ \\
Pielonefritis & 1 & $3.44 \%$ \\
\hline
\end{tabular}

Mortalidad. Se presentaron en esta serie dos muertes para un $6.89 \%$ con una desviación standard de más - menos $4.5 \%$. El primer caso se trata de una paciente de 28 años de edad, quien confesó antecedentes de maniobras abortivas en tres oportunidades. Ingresó con diagnóstico de pelviperitonitis y seis días después es intervenida con diagnóstico de peritonitis generalizada, en el post-operatorio presentó una fístula ileal y 
desequilibrio hidroelectrolítico que asociado a la infección determinaron la muerte.

El segundo caso es el de una paciente de 31 años, quien ingresa al Servicio con diagnóstico de sepsis estado III, con antecedentes de maniobras abortivas, la cual es intervenida de urgencia el día de su ingreso. Al tercer día post-operatorio entró en estado de coma ácido cetócico, con glicemia de 586 mgrs.\%, glicosuria y cetonuria de cuatro cruces. A la autopsia se encontró además del proceso infeccioso una severa lesión renal (Kimmestiel Wilson).

Controles. Los controles no son tan completos como se desea debido a la falta de colaboración voluntaria - involuntaria de las pacientes, sinembargo, se realizaron 20 controles a 13 pacientes siendo el examen ginecológico, la temperatura y la V. S. $G$. normales en 16 casos. Con masas anexiales pequeñas o empastamiento de los mismos 4 casos, de los cuales dos se hicieron negativos con tratamiento médico ambulatorio. Los otros dos no tienen más controles.

Hubo dos casos de reingreso: uno por continuar la infección de la herida quirúrgica y presentar Hepatitis Viral, se trató médicamente y en más o menos 8 días cedió la sintomatología saliendo la paciente en aceptables condiciones generales.

El otro caso es el de una paciente joven la cual presentaba un problema Psiconeurótico de dependencia, consultando en dos o tres oportunidades a Urgencias por intenso dolor abdominal e incapacidad para trabajar. Se hospitalizó y tanto el examen clínico como los exámenes de laboratorio y estudio radiológico resultaron negativos. Se le dio salida después de 8 días de permanencia en el Servicio sin tratamiento médico y no ha vuelto a controles.

\section{CUADRO Nㄴ 14}

CONTROLES

\begin{tabular}{lrc}
\hline & Casos & Porcentaje \\
\hline Controles negativos & 16 & $80 \%$ \\
Masas anexiales & 2 & $10 \%$ \\
Reingresos & 2 & $10 \%$ \\
\hline
\end{tabular}

\section{COMENTARIO}

En el trabajo presentado por el profesor Rafael Peralta Cayón (2) en 1947 para Agregación de la Clínica Obstétrica de la Universidad Nal. y que comprende una revisión que va de 1912 a 1946 se encontraron 107 casos de Peritonitis generalizada de los cuales murieron 103 para un $96.2 \%$ de mortalidad y 68 casos de Pelviperitonitis de los cuales murieron 42 para un $67.74 \%$ de mortalidad, lo cual indica que tanto los métodos como técnicas quirúrgicas y seguramente los antibióticos han mejorado notablemente hasta el punto de reducir la mortalidad al $6.89 \%$.

Los mejores resultados se obtienen cuando se hace el diagnóstico oportunamente (3) y se resuelve la conducta quirúrgica inmediatamente esté indicada lo mismo que cuando el proceso infeccioso no se encuentra asociado a ninguna otra patología ya que en estos casos como se vió antes el pronóstico es grave. Así en nuestra serie las dos defunciones correspondieron a la asociación en un caso de fístula lleal post-operatoria y en el otro de una nefropatía diabética severa.

Las complicaciones más frecuentes son la infección de la herida quirúrgica, neumonía, absceso subfrénico 
(4), las cuales han respondido al tratamiento médico a base de dosis masivas de antibióticos.

La mayoría de las Pelvi o Peritonitis son debidas probablemente a perforaciones uterinas durante las maniobras abortivas (5), aunque este hecho es difícil de evidenciar ya que durante la revisión de la cavidad pélvica en el acto quirúrgico solamente se puede sospechar por las adherencias del epiplón mayor a las paredes uterinas y en contados casos se puede comprobar la perforación.

Hay casos en los cuales es evidente el proceso infeccioso ascendente. La vía hematógena de propagación resulta difícil de comprobar pues los hemocultivos fueron todos negativos.

\section{CONCLUSIONES}

1․ El alto índice de infección peritoneal en estas pacientes es debido en la mayoría a maniobras abortivas con perforación uterina y a la consulta tardía.

2. El diagnóstico de la Pelvi o Peritonitis es más clínico que de laboratorio y el criterio para manejarla lo dá la familiarización del médico con estos cuadros (7).

3․ La técnica quirúrgica a seguir la impone la forma como haya evolucionado la infección así (8): se practicó colpotomía previa colpocentesis cuando hubo franco abombamiento del fondo de saco posterior $y$ el proceso infeccioso estaba localizado a la pelvis. Se debe procurar siempre practicar raspado uterino. En las peritonitis generalizadas que no cedieron al tratamiento médico se practicó laparotomía, haciendo exploración de la cavidad pélvica y abdominal si la reacción inflamatoria no era $\tan$ severa que dificultara o hiciera imposible dicha exploración y en tal caso solamente se hizo drenaje del material purulento, lavado de la cavidad abdominal con suero fisiológico a temperatura corporal y dejando 500 mgrs. de rifamicina en cavidad, drenes de Penrosse y puntos de tensión en la pared.

De lo anteriormente anotado se deduce que no se puede establecer un tratamiento quirúrgico determinado, sino que este depende del caso en particular y de acuerdo con la experiencia del Médico tratante.

4 . Debido al mejoramiento de métodos, técnicas y empleo de antibióticos el porcentaje de mortalidad ha disminuído notoriamente.

\section{RESUMEN}

1. Se presenta un estudio sobre 20 casos de peritonitis y 9 de Pelviperitonitis tratados en el Servicio de Sépticas del I. M. I. en un período de seis meses sobre un total de 200 pacientes.

2. Para el diagnóstico se tuvo en cuenta principalmente la sintomatología de ingreso, el antecedente de maniobras abortivas y el cuadro clínico.

3․ La asociación de gérmenes patógenos más frecuente fue la de E. Coli y Estafilococo Albus no Hemolítico.

4. El tratamiento se hizo a base de dosis masivas de Penicilina Cristalina 30 a 60 millones al día por vía intravenosa durante 5 a 12 días, asociada a cloranfenicol 3 a 4 grs. al día durante 8 a 10 días por vía intravenosa (6) y cirugía cuando el proceso infeccioso no cedió al tratamiento médico. En todos los casos de Laparotomía se dejaron 500 mgrs. 
de Rifamicina en la cavidad abdominal, drenes y Penrosse y puntos de tensión en la pared abdominal.

5 . Se presentaron dos casos de muerte en uno de los cuales el proceso infeccioso estaba asociado a un Síndrome de Kimmestiel Wilson y en el otro a una fístula ileal postoperatoria.

\section{BIBLIOGRAFIA}

1 NEWIRTH S., FRIEDMAN E.: Septic Abortion: concept of management. Year Book Obst. \& Gynec. Series: 48, 1963/64.

2 PERALTA CAYON R.: Peritonitis y pelviperitonitis. Arch. de la U. N. de Colombia. 66, 1947.

3 ADCOCK L., HAKANSON E.: Vascular Collap- se complicating septic abortion. Am. J. Obst. \& Gynec. 79, 3: 516, March, 1960.

4 BERENS J. J.: Subphrenic abscess. Surg. Obst. \& Gynec. 96: 463, 1953.

5 DEANE R., RUSSEL K.: Enterobacillary septicemia and bacterial shock in septic abortion. Am. J. Obst. \& Gynec. 79, 3: 528, March, 1960

6 PLANELLES J., JARITONOVA A.: Efectos nocivos consecutivos al empleo de antibióticos en el tratamiento de las enfermedades infecciosas. Primera Ed.: 23-48-104, Progreso, Moscú, 1955.

7 CRISTOPHER P. H.: Tratado de Patología Quirúrgica. Octava Ed. 434, Davis Interamericana, México, 1965.

8 BUKA N., WELTON J., TENNY B.: Upper gastrointestinal hemorrhage after septic abortion. Am. J. Obst. \& Gynec. 91, 4: 504, February 15/65. 